\title{
Undergraduate Students' Perspectives of Essential Instructor Qualities
}

\author{
Beth A. Trammell ${ }^{1}$ and Rosalie S. Aldrich ${ }^{2}$
}

Abstract: There are many variables that impact a classroom experience including the instructor, the student, and the class itself. Much research has been done in the area of undergraduate student expectations and preferences for instructors, course format, etc. This paper explores how specific student characteristics such as first-generation status, age, class level, and format impact students' perception of what makes a good instructor. By understanding what instructor qualities these students appreciate, instructors can tailor their behavior to improve student learning and retention. Results suggest few differences within and between these groups of students. However, students had strong preferences for a high number of positive instructor characteristics, suggesting the possibility of overly optimistic and unrealistic preferences. Implications of this and suggestions for how instructors can better accommodate the preferences of students are discussed.

Keywords: undergraduate student preferences, first generation college students, student instructor preferences

The importance of matching student and instructor expectations cannot be overemphasized. When instructors are explicit about expectations, even high expectations, students have better academic success in the short-term (i.e., better exam grades) and long-term (i.e., higher graduation rates and better retention) (Blose, 1999). Taken further, it has been suggested for more than three decades that many students drop out of college because of the gap between their expectations for the college experience and the reality of their actual college experience (Tinto, Goodsell-Love, \& Russo, 1993). Faculty are becoming more interested in understanding these expectations so they may enhance students' understanding and learning of the course material, as well as increase students' satisfaction with courses and retention. By gaining this understanding, faculty may be able to have more flexibility within teaching and/or adjusting those student expectations as necessary.

The literature that explores undergraduate students' expectations about their classroom experience is widely varied. Some examples of mismatched expectations include student perception of work required for class outside of class time (Hassel \& Lourey, 2005), time spent reading the textbook (Connor-Greene, 2000; Sikorski et al., 2001), the impact and amount of instructor presence (Shea, Pickett, \& Pelz, 2003), as well as characteristics of a good instructor (Sheridan \& Kelly, 2010). There are many aspects to the college experience that can impact how

\footnotetext{
${ }^{1}$ Department of Psychology, Indiana University East, 2325 Chester Blvd., Richmond, IN, 47374, batramme@iue.edu

${ }^{2}$ Department of Communication Studies, Indiana University East
} 
well a student does, and although all of these expectations impact the students' learning to some degree, this paper will look specifically at students' perceptions of what makes a good instructor. The purpose of this paper is to explore what different groups of undergraduate students, specifically: first generation versus non-first generation, students in lower-level classes versus upper level classes, traditional versus non-traditional-aged students, online versus face-to-face classes, perceive are qualities of a good college instructor (e.g., interpersonal characteristics, content expertise, teaching skill. etc.).

\section{Literature Review}

One goal of instructors is to teach new information or change the way students currently think about information. For instance, if the student has inaccurate information about a topic, it is the role of the instructor to provide information in order to help the student understand the concept or process more accurately and completely. To do that, one must consider two important components to how a learner (students) receives a message from a communicator (instructors). These include characteristics of the communicator delivering the message and the manner in which the information is delivered. In a recent study on general education classes, students consistently rated "communication of ideas and information" as the most important item for high satisfaction within the course (Pepe \& Wang, 2012). Along those same lines, researchers have examined personality characteristics that define who the instructor is such as approachable, funny, or caring (Andreson, 2000; Hill et al., 2003; Swanson et al., 2005) and the knowledge and expertise that the instructor has (Pozo-Munoz, Rebolloso-Pacheco, \& Fernandez-Ramirez, 2000). Other studies explored the impact of instructor behaviors related to what the instructor does. For example, does the instructor respond quickly, is the instructor organized, and so on (Chuckering \& Gamson, 1987). By pulling all of these components together, it is possible to begin to understand the desires and expectations of students.

One interesting study asked students to "build" a professor, essentially asking students what they believed would be ideal qualities in an instructor (Senko, Pickett, \& Pelz, 2003). By asking students to rank the professor qualities, they conceptualized traits that students found to be "necessities" versus those that were "luxuries." In other words, the professor qualities that were most highly ranked were seen as necessary traits, and those of a lower rank were luxuries. In doing this, Senko and colleagues (2012) found that students most valued enthusiasm, but also highly valued topic expertise, clarity about successful student achievement, clear presentation style, and reasonable workload. One quality noted in their sample as being a luxury was a warm/compassionate personality. This suggests that when forced to choose certain characteristics of instructors, students have varying desires of what they think is the ideal personality and level of expertise in the instructor, as well as method of course design.

Keeley, Smith, and Buskist (2006) proposed a model of "master teaching" that attempts to define the behavioral characteristics of instructors that are most satisfactory to students. They created the Teacher Behaviors Checklist (TBC) to examine students' perceptions of specific traits and the frequency at which they see these traits displayed by their instructor. This study is unique in that the authors provided behavioral examples for each trait. For instance, when asking how "accessible" the instructor is, the checklist asks students to consider if the instructor posts office hours or gives out contact information. Another trait on the checklist is Approachable/Personable, which includes whether the instructor smiles, greets students, initiates conversations, invites questions, and responds respectfully to student comments. Although this 
checklist gives objective, behavioral examples of instructor personality characteristics, those examples may not be the only way in which an instructor may be accessible or approachable. Nonetheless, Keeley and colleagues (2006) found support for studying successful teaching by focusing on two dimensions: 1) the caring and supportive dimension, and 2) the professional competency and communication skills dimension. Using this, we include personality characteristics under the caring/supportive dimension, and instructor behaviors and knowledge under the professional competency and communication skills dimension. It is this framework that we will use to describe student preferences.

\section{Who the instructor is (personality characteristics)}

Obviously, since the instructor is responsible for most aspects of the college course, including the "tone" of the classroom, the types of activities assigned, and interactions within the classroom, that instructor plays a major part on the students' learning. However, what is less obvious is the impact that the instructor's personality has on overall student learning and how a student's preferences may come into play.

Personality characteristics can be understood as innate within the instructor regardless of the level of training he or she has in the content area. Simply, the instructor's personality reflects who that person is both in the classroom and outside of the classroom. Especially important in this context are those parts of the instructor's personality that are shared within the classroom setting. Previous research suggests that one of the most important instructor attributes as described by students is empathy (Jaasma \& Koper, 1999), particularly as it pertains to the busyness of students' lives (Sheridan \& Kelly, 2013). Specifically, students indicated they appreciated when instructors were considerate of things getting in the way of students completing work due to obligations outside the classroom (Sheridan \& Kelly, 2013). This is an important finding as many instructors may struggle to find the balance between maintaining standards while also allowing students some leeway in terms of missing deadlines due to outside obligations. In fact, in the majority of studies, empathy and/or caring was consistently a desired characteristic of professors (Andreson, 2000; Hill et al., 2003; Swanson et al., 2005). Although it is important to maintain a professional relationship with students, this suggests students desire that relationship to maintain a real-life, caring quality as well. Borrowing from counseling psychology, the idea of building rapport with students, showing them empathy and caring, may be an important part of meeting the students' needs. Even in large lecture classrooms (with upwards of 300 students), it has been suggested that students still expect to have a relationship with their instructor that includes empathetic responding to the individual student's needs (Darlaston-Jones et al., 2003).

Studies have also suggested successful instructors display a strong sense of enthusiasm (Andreson, 2000; Lammers \& Murphy, 2002; Sander et al., 2000). In addition, having a good sense of humor (Adamson, O'Kane, \& Shevlin, 2005), openness to students' feedback, and approachability have been noted to be important to students (Faranda \& Clarke, 2004). Instructors should also show a willingness to answer questions and have flexibility to explain things in a number of ways to help students at every academic level (Voss, Gruber, \& Szmigin, 2007). Students also report higher satisfaction with instructors who treat them with respect and build strong interpersonal relationships with them (Faranda \& Clarke, 2004).

Taken together, traits such as caring, enthusiastic, approachable, inspiring, fair, wellprepared and helpful are some of the most common traits reported to be desirable (See Buskist,

Journal of the Scholarship of Teaching and Learning, Vol. 16, No. 1, February 2016.

Josotl.Indiana.edu 
Sikorski, Buckley, \& Saville, 2002). In general, it seems that students simply want professors who are genuine people. This is not to say that having strong teaching skills and expertise in the content area are not important; rather, these things appear to be often overlooked by students so long as the instructor is genuinely interested in their learning (by displaying outward empathy, caring, enthusiasm). Without some level of knowledge and competence in the content area, the instructor would be nothing more than a peer in the class with the students. Instructor competence and expertise is discussed in the following section.

\section{What the instructor does (Instructor behaviors and knowledge)}

Even if an instructor has ideal personality characteristics and is knowledgeable in the content area, without organizational skills, the students are almost always unsatisfied with the course (Shea, Pickett, \& Pelz, 2003). Particularly in the online classroom, well-developed organizational skills are a must. When students do not have a scheduled class time to arrive on campus (inherently providing organizational structure for them), they are likely to get lost in the cyber world without class organization (Song, Singleton, Hill, \& Koh, 2004). Even in the seated classroom, it has been noted that organizational skills are highly valued by students (Pepe \& Wang, 2012), as it makes the communication of knowledge from instructor to student more fluid. Beyond maintaining organization throughout the course, the way in which the course is organized is also of utmost importance. It has been suggested that many college-level instructors are unaware of the importance of course design:

"Much of the creativity and power in teaching lies in the design of the curriculum: the choice of texts and ideas which become the focus of study, the planning of experiences for students and the means by which achievement is assessed. These define the boundaries of the experience for students." (Toohey, 1999, p, 45).

Recently, a tool was established to clearly outline course design and organization for instructors. Quality Matters provides instructors with training on how to streamline course design to improve student learning, engagement, and satisfaction in online learning environments (Legon \& Adair, 2013). By applying the Quality Matters rubric, a method for applying quality standards to course design based on research (Ramsey, 2000), instructors are creating a more organized environment for student learning. Although the rubric was intended to be used within online classes, most face-to-face classes use some form of learning management system (i.e., Moodle, Canvas, Blackboard, etc.) that is online for assignments, tests, quizzes, gradebook, etc. As such, the Quality Matters rubric could be a good place to start to organize even face-to-face classes.

In addition to being organized, students need instructors who provide prompt feedback on their work. Students are equipped to learn more quickly and efficiently when having a sense of what they are doing right and a means by which they can correct that which they are doing wrong (Hounsell, 2003). Responding quickly to students about their performance is the best way to help learn new information because if feedback is not given quickly, it allows more time for the wrong information to be held and can be more challenging to correct. According to Chuckering and Gamson (1987), one of the most highly recognized models for undergraduate education, prompt feedback is listed as one of the seven principles for good practice in higher education. It should also be noted that a lack of feedback can increase a student's frustration and level of anxiety, particularly in online courses (Hara, 2000).

Journal of the Scholarship of Teaching and Learning, Vol. 16, No. 1, February 2016. Josotl.Indiana.edu 
Instructor competence and expertise, including teaching skills and pedagogy, have been linked to overall student satisfaction and student learning (Voss, Gruber, \& Szmigin, 2007). As mentioned, although it is important for instructors to have positive personality traits, it is imperative that they are competent and have at least a minimal level of expertise in the content area and the competence to deliver that expertise to others. Most instructors receive advanced training in a content area (either Master's or Doctoral training) which gives them the content knowledge required to teach a certain course. What is not necessarily gained during an instructor's graduate training is how to transmit that information via teaching methodologies to novice learners. Reneau (2011) reviewed the literature on activities during doctoral training that support junior faculty in effective teaching at the college level and suggested five key activities including 1. Taking a course or seminar on college teaching, 2. Teaching a class, 3. Mentoring (e.g., receiving feedback on teaching, discussions about teaching philosophy), 4. Self-reflection, and 5. Opportunities to engage in all aspects of research and developing a range of teaching skills. Even with the availability of teaching assistantships in graduate training, these positions are not necessarily intended to give the graduate trainee the supervision and skills-training to be a good instructor (Silverman, 2003). Thus, it leaves instructors with little, if any, formal training on how to actually go about being a good instructor (Utecht \& Tullous, 2009).

As the climate in higher education continues to adapt, nearly two decades ago it was suggested there be a shift from an "Instruction Paradigm", whereby instructors conduct lectures solely as a means to transfer knowledge from instructors to students, to a "Learning Paradigm" whereby instructors are charged with providing an enriching environment that "elicits student discovery and construction of knowledge" (Barr \& Tagg, 1995, p. 16). This shift requires strong knowledge and competency within the area of teaching, as well as strong teaching skills. This same idea was first introduced by Shulman's work of K-12 teacher knowledge in the 1980s, suggesting good teachers require both subject knowledge and pedagogical knowledge (Shulman, 1987). Shulman described pedagogical content knowledge as the most useful, most regularly taught information within the subject area (e.g., the most representative examples, demonstrations, research studies, etc.). This same idea can be transposed onto the undergraduate classroom. It can be understood as a skillset unique to teachers who take content, organize it and communicate it to others through a pedagogical process so the learners can comprehend it (Major \& Palmer, 2002). In short, although students want professors who are genuine people, they also highly value instructors who have competence and expertise (Pozo-Munoz, et. al., 2000). With this, we will now explore student characteristics that may impact what they prefer in instructors.

\section{Student Characteristics and Class Format Impact Preferences}

Intuitively, it is likely that there are individual differences within students that impact individual preferences for qualities of instructors. Although literature studying first-generation college students is growing, there is still little that is known about how these students may be different with regard to their preferences for ideal instructors. Notably, since first-generation college students' parents do not have experience in college classrooms, it's possible that firstgeneration college students' preferences may be unrealistic. Also, it may be true that students in introductory courses have different preferences than students in advanced courses, as they have had more experience in college (in addition to interaction with instructors) that may impact those preferences. Beyond that, it may be less about course level and more about age of the student.

Journal of the Scholarship of Teaching and Learning, Vol. 16, No. 1, February 2016. 
Finally, since online students have less, if any, face-to-face contact with their instructor, it is possible that this impacts their perceptions of quality instructors.

First generation students. First generation students have been defined as students who have parents that have had no more than a high school education, thus, the student was a member of the first generation in the immediate family to attend college (Warburton, Bugarin, \& Nunez, 2001). First generation students may be particularly vulnerable to skewed expectations of the college classroom because their parents may not be able to guide them. In a comprehensive study by the National Center for Education Statistics, results suggested first-generation college students were more likely to drop out of college early and/or transfer to a different university prior to obtaining their degree (Warburton et al., 2001). Indeed, students whose parents attained a bachelor's degree (or higher) were more likely to complete their degree than students whose parents did not attend college (Warburton et al., 2001). This suggests that in some way, the expectations these students have for college classes, college professors, and/or what the college experience is somehow skewed in such a way that they are less successful than their non-first generation counterparts. Another study noted that first generation college students engaged in lower academic engagement, including interacting with faculty (Soria \& Stebleton, 2012).

Collier and Morgan (2008) proposed a conceptual model of student success to include understanding the college student role in addition to mastering course content. They propose that much of what college entails is not necessarily fully encompassed in the content of what students learn in their courses; rather it is in the process of learning how to learn in the college classroom. For instance, learning how to interact professionally with the instructor; how to manage the expectations of multiple professors in a single semester; and how to navigate technology in their courses can be quite challenging for students. None of these are directly related to the content of most courses, yet most instructors would argue are a "requirement" to do well in their course. In fact, anecdotal evidence suggests many instructors expect that their students already know how to do these things and thus do not spend class time devoted to teaching these things explicitly. In their model, Collier and Morgan argue that first generation college students are particularly susceptible to misunderstandings in what the student role entails due to lack of parental modeling (2008). For instructors teaching classes with many first-generation students, it may be necessary to spend more time teaching students how to be successful college students, as well as how to learn the content of that specific course. Therefore, the following hypothesis is posited:

H1: First-generation students will have different perceptions of what qualities make a good instructor than non first-generation students.

Class level expectations. For decades, it has been suggested that college students undergo a number of changes from their freshman year to their senior year. Studies have examined college impacts how the college student experiences changes in attitudes, values, thinking skills, and personality (Lehmann, 1963; Pascarella \& Terenzini 2005; Webster, Freedman, \& Heist, 1962). This suggests that as the student matures from their first year to their third or fourth year, they may have varying preferences and expectations of their instructors as well. It has been suggested students move from attitudes at the beginning of their college career whereby they were expecting "received knowledge" - where instructors impart knowledge to them (For a review, see Redish, Saul, \& Steinberg, 1998). Students then move toward a more sophisticated attitude whereby information is provided by the instructor, but that this information is still up for acceptance and interpretation from the learner (Redish, Saul, \& Steinberg, 1998). All of this suggests students within lower-level courses may have different expectations of the instructor 
(lower-level students may expect higher levels of content knowledge, expertise, than their upperlevel counterparts). Therefore, the following hypothesis is posed:

H2: Students in 100 and 200-level classes will have different perceptions of what qualities make a good instructor than those in upper level classes.

Age. It has been suggested that there are metacognitive differences between students who are traditional age college students (18-23 years of age) and those that are non-traditional (24+ years) (Justice \& Dornan, 2001). These changes may impact what types of preferences traditional students have from those that are older. A recent exploratory study suggested older students emphasize a desire for instructors to be more knowledgeable, rather than personable (Hill \& Christian, 2012). However, it was also noted that students preferred a balance between instructor competence and positive personality traits. Another study noted traditional-aged students described ideal instructors as fun/funny, engaging, not overly challenging, and having active instructional activities (Strage, 2008). Alternatively, the non-traditional students in that sample wanted instructors who were more rigorous, serious, and encouraging preparation for "real life" experiences (Strage, 2008). Because there is limited research in this area as well, we pose the following research question:

RQ1: Is there a difference between traditional and non-traditional students regarding which teacher qualities they find important?

Class format expectations. Since the early 1990s, as technologies continue to improve for online education, the proposition that online education differs from traditional seated classroom learning has been an ongoing debate. Opponents of online education argue there can be no replacement for the face-to-face interaction that students get from the live interaction with instructors; whereas proponents of online education argue online education can be as effective if certain course design elements are met (Hadidi \& Sung, 2000). From the student perspective, most students enroll in online classes because they are attracted to the flexibility of learning on their own time (Song, Singleton, Hill, \& Koh, 2004). Among other things, frequent communication and prompt feedback from instructors was a clear expectation from the online learners (Mupinga, Nora, \& Yaw, 2006). Interestingly, Mupinga and colleagues found that students expected the online course to be similar in rigor and demand as the traditional face-toface courses.

To this point, many qualities of the instructor have been discussed that may be challenging to witness without face-to-face interaction. Even with video or audio lectures in the online classroom, it is quite difficult to replicate the minor social nuances that occur in live discussion in the classroom. Nonetheless, little research has been done on whether or not students' expectations vary based on class format. Because there is limited research in this area we pose the following research question:

RQ2: Is there a difference based on class format (online, face-to-face, or hybrid) in student perceptions of what qualities makes a good instructor?

\section{Methods}

\section{Participants and Procedures}

Participants $(n=132)$ were drawn from undergraduate students at a small Midwest university. Participation was voluntary. Some participated to fulfill a course research 
requirement where an alternative assignment was available if they chose not to participate. Others participated to receive extra credit (this distinction depended on the course instructor). Participants did not receive compensation. The participants were instructed to visit a web address where they completed the online survey on their own. The sample was composed of 100 females (75.8\%) and 32 males (24.2\%), ranging in age from 18 to $64(M=25.36, S D=9.53)$. The majority of the sample was Caucasian (88.6\%). Of the participants $52(39.4 \%)$ were first generation. There were 90 students aged 18-23 (traditional) and 42 students 24 years or older (nontraditional). Many students indicated that they take more in-person classes $(n=78,59.1 \%)$ than online $(n=41,31.1 \%)$ or hybrid courses $(n=13,9.8 \%)$.

After informed consent was obtained participants were asked to complete questions adapted from the University Students' Expectations of Teaching (USET) questionnaire created by Sander et al. (2000). Additionally, participants answered demographic questions and questions related to year in school, first generation status, class format of most classes taken and currently taking, and teacher qualities. Participants were asked to respond to the following prompt: "What do you believe to be the essential qualities of a good teacher for your course?" for each of the 11 teacher qualities (e.g., A good instructor should be approachable; A good instructor should have strong teaching skills, etc.). Their responses were measured on a 5 point Likert scale ranging from strongly disagree to strongly agree. They include questions about teacher approachableness, teaching skills, enthusiasm, knowledge, organization, and responsiveness whereby important qualities for an effective instructor and higher scores indicate greater agreement (see Table 1). The Cronbach's Alpha for the 11 item Likert scale was .944. The questionnaire was anonymous (Survey Monkey).

\section{Table 1. Mean and Standard Deviation for Teacher Quality Scale}

$\begin{array}{lll}\text { Quality } & \text { Mean } & \text { Standard Deviation } \\ \text { Approachable } & 4.75 & .85 \\ \text { Strong Teaching Skills } & 4.72 & .87 \\ \text { Enthusiastic } & 4.45 & 1.10 \\ \text { Positive Outlook } & 4.52 & .94 \\ \text { Knowledgeable about the course content } & 4.69 & .97 \\ \text { Organized } & 4.61 & .91 \\ \text { Knowledgeable about technology } & 4.42 & .93 \\ \text { Quick email/phone call responses } & 4.36 & .99 \\ \text { Consistent } & 4.48 & 1.07 \\ \text { Empathetic } & 2.64 & 1.02 \\ \text { Friendly } & 4.45 & .95\end{array}$

\section{Results}

To address hypothesis 1, which predicted that first-generation students would have different perceptions of what makes a good instructor than non-first generation students was tested with one-way analysis of variances (ANOVAs). There was not a significant difference between first generation students and non-first generation students for any of the teacher qualities (see Table 2); therefore, H1 was not supported. 


\section{Table 2. First-Generation vs. Non-First Generation Students and Teacher Qualities}

$\begin{array}{ll}\text { Quality } & \text { Significance (p-value) } \\ \text { Approachable } & .84 \\ \text { Strong Teaching Skills } & .97 \\ \text { Enthusiastic } & .96 \\ \text { Positive Outlook } & .99 \\ \text { Knowledgeable about the course content } & .57 \\ \text { Organized } & .49 \\ \text { Knowledgeable about technology } & .27 \\ \text { Quick email/phone call responses } & .37 \\ \text { Consistent } & .13 \\ \text { Empathetic } & .26 \\ \text { Friendly } & .23\end{array}$

Hypothesis two predicted there would be a difference in opinion of qualities of an effective teacher depending on the level of the class they were taking (e.g., 100, 200). A one-way ANOVA was used to test for differences among the class levels and again, no significant differences were found (see Table 3). Therefore, H2 was not supported.

\section{Table 3. Level of Class and Teacher Qualities}

Quality

Approachable

Strong Teaching Skills

Enthusiastic

Positive Outlook

Knowledgeable about the course content

Organized

Knowledgeable about technology

Quick email/phone call responses

Consistent

Empathetic

Friendly
Significance (p-value)

.50

.33

.38

.63

.96

.52

.53

.37

.55

.17

.09

An independent samples t-test was conducted to determine if traditional and nontraditional students differed in the teacher qualities they found important (RQ1). There were two significant differences found. There was a significant difference for teacher enthusiasm, $t(121)=2.81, \mathrm{p}<.01$, between traditional students $(M=3.61, S D=1.72)$ and nontraditional students $(M=4.51, S D=1.54)$, with an effect size of .551 (Cohen's d), which is considered large. There was also a significant difference for teacher responsiveness, $t(125)=-3.03, p<.01$, between 
traditional students $(M=4.36, S D=1.51)$ and nontraditional students $(M=3.46, S D=1.66)$, with an effect size of .567, which is again, is considered large.

The second research question addressed if there was a difference in perception about what teacher qualities were essential to be a good instructor depending on how the class was delivered (i.e., online, face-to-face, or hybrid). One-way ANOVAs were performed with how the class was delivered as the independent variable and the teacher qualities as the dependent variables. The only significant difference was found for organization, $F(2,115)=3.26, p=.04$. Post hoc comparisons using the Tukey HSD test indicated that the mean score for on-campus format $(M=4.64, S D=.62)$ was only approaching a significant difference at $p=.067$ with the online format $(M=4.88, S D=.33)$, and neither were statistically different for the hybrid method of course delivery $(M=4.57, S D=.534)$. Taken together, these results suggest that organization is considered an equally important teacher quality across methods of course delivery.

\section{Discussion}

Despite anecdotal suggestions that students within various groups have different expectations of what to expect from instructors, results here suggest different groups tend to have similar expectations of their college professors. There were no significant differences in what students in lower-level classes expected from their instructors compared to upper-level classes. Similarly, first-generation college students appear to have similar expectations of their instructors as non-first generation college students. Thus, it does not appear to be as complex a picture for instructors of multi-level courses.

One thing that is striking is the overall expectation that students have of instructors. Results here suggest students have high expectations for instructors to have many positive personality traits, as well as strong teaching skills and content knowledge. Students from this sample reported strong agreement with wanting an instructor who was approachable, enthusiastic, positive, knowledgeable (about content and technology), organized, consistent, friendly, quick to respond, and strong teaching skills. Together, this may suggest that students have unrealistically high expectations for instructors. Taken further, if expectations are unrealistically high, it is likely that instructors will not meet those expectations of students, only leaving those students to be disappointed and/or unsatisfied with the course.

One surprising finding was the low desire for the teacher to be empathetic. This challenges what is currently suggested in the research. One possible explanation for this finding may be the students' lack of understanding of the term. Perhaps it would be more fruitful in future studies to provide examples of each quality instead of just naming them.

Another interesting finding is that students within the online classroom did not have different preferences for instructors than did those in traditional face-to-face classrooms. Their expectations for strong personality characteristics was still high. This is of particular note because it can be more challenging for instructors to show personality traits, strong teaching skills, and interpersonal enthusiasm within the online forum (Smith, Ferguson, \& Caris, 2001). Online instructing presents the unique challenges of maintaining organization as well as expressing one's personality. Implementing interactive technology such as chat rooms and video conferencing may prove advantageous in establishing a more personal instructor/student relationship.

Results here suggest a significant difference regarding organization, but all other instructor qualities were preferred from students regardless of the delivery. As such, it is critical 
that instructors are able to show students they are approachable, enthusiastic, positive, knowledgeable (about content and technology), consistent, friendly, quick to respond, and strong teaching skills. This is somewhat inconsistent to previous research that suggested empathy and friendliness to be more important (Sheridan \& Kelly, 2010). Implications for this include being more aware that pedagogical ideas may be as important as interpersonal factors. With this evidence to suggest there may be high expectations from all types of students, it is critical that faculty obtain training about how to develop strong, organized courses, in addition to allowing their personalities to shine through. Shea and colleagues (2003) argued for faculty development in instructional design to impact both student satisfaction and learning.

Limitations of this study include having a disproportionate number of female student respondents $(\sim 76 \%)$. Research suggests there are differences in gender related to desired teacher qualities (Minor, Onwuegbuzie, Witcher \& James, 2002). For example, men tend to endorse teacher characteristics associated with being an effective classroom manager more than women (Minor et al., 2002). Because the sample is overwhelmingly female these results cannot be generalized to male college students. Similarly, the sample here was mostly Caucasian and may not be representative of preferences for students from other ethnic backgrounds. As with many survey studies, a convenience sample was used and data was collected at only one point in time. It would be beneficial to collect data from a randomly selected sample and follow them longitudinally through their college careers to examine if their desires for teachers to possess certain qualities changes over the course of time. Finally, the questionnaire asked students about their preferences of mostly positive instructor qualities, students may have been more skewed to answer in a positive direction. Future surveys should also include more instructor qualities that may be perceived as less positive.

Expectations of students in higher education have been an increasingly important topic as this is directly related to student learning and retention. Faculty and instructors are becoming more interested in understanding these expectations so as to increase students' satisfaction and better meet student needs. To date, there is little research to explore differences in desired teacher qualities from different student groups (i.e., traditional vs. nontraditional, first generation vs. non first generation) and different class formats (online vs. face-to-face). This study found there were little differences in overall student desires for teacher qualities; however, these ideals may be unattainable by any one professor/instructor. It becomes clear that those teaching the course need to be cognizant of the qualities students prefer and students need to be made aware of realistic professor/instructor characteristics. 


\section{References}

Adamson, G., D. O'Kane, \& M. Shevlin. (2005). Students' ratings of teaching effectiveness: A laughing matter? Psychological Reports 96, 225-226.

Andreson, L. (2000), "Teaching development in higher education as scholarly practice: A reply to Rowland et al. turning academics into teachers", Teaching in Higher Education, 5(1), 23-31.

Barr, R. B., \& Tagg, J. (1995). From teaching to learning-A new paradigm for undergraduate education. Change: The magazine of higher learning, 27(6), 12-26.

Blose, G. (1999). Modeled retention and graduation rates: Calculating expected retention and graduation rates for multicampus university systems. New directions for higher education, 1999(108), 69-86.

Buskist, W., Sikorski, J., Buckley, T., \& Saville, B. K. (2002). Elements of master teaching. The teaching of psychology: Essays in honor of Wilbert J. McKeachie and Charles L. Brewer, 27-39.

Chickering, A. W., \& Gamson, Z. F. (1987). Seven principles for good practice in undergraduate education. Retrieved from: http://www.aahea.org/articles/sevenprinciples1987.htm on March 25, 2015.

Collier, P. J., \& Morgan, D. L. (2008). “Is that paper really due today?”: Differences in firstgeneration and traditional college students' understandings of faculty expectations. Higher Education, 55(4), 425-446.

Darlaston-Jones, D. K., Pike, L., Cohen, L., Young, A. H., Haunold, S., \& Drew, N. M. (2003). Are they being served? Student expectations of higher education. Issues in Educational Research, 13(1), 31-52.

Dennen, V. P., Aubteen Darabi, A., \& Smith, L. J. (2007). Instructor-learner interaction in online courses: The relative perceived importance of particular instructor actions on performance and satisfaction. Distance Education, 28(1), 65-79.

Faranda, W. T., \& Clarke, I. (2004). Student observations of outstanding teaching: Implications for marketing educators. Journal of Marketing Education, 26(3), 271-281.

Hadidi, R., \& Sung, C. H. (2000). Pedagogy of online instruction-can it be as good as face-toface? AMCIS 2000 Proceedings, 2061-2065.

Hara, N. (2000). Student distress in a web-based distance education course. Information, Communication \& Society, 3(4), 557-579.

Hill, J. S., \& Christian, T. Y. (2012). College student perceptions and ideals of teaching: An Journal of the Scholarship of Teaching and Learning, Vol. 16, No. 1, February 2016. 
exploratory pilot study. College Student Journal, 46(3), 589-602.

Hill, Y., Lomas, L. and MacGregor, J. (2003), "Students' perceptions of quality in higher education", Quality Assurance in Education, 11(1), 15-20.

Hounsell, D. (2003). Student feedback, Learning and Development. In M. Slowey, \& D. Watson (Eds.), Higher Education and the Lifecourse. (pp. 67-78). SRHE \& Open University Press.

Hovland, C. I., Janis, I. L., \& Kelley, H. H. (1953). Communication and persuasion; Psychological Studies of Opinion Change. New Haven, CT, US: Yale University Press.

Jaasma, M. A., \& Koper, R. J. (1999). The relationship of student-faculty out-of-class communication to instructor immediacy and trust and to student motivation. Communication Education, 48(1), 41-47.

Justice, E. M., \& Dornan, T. M. (2001). Metacognitive differences between traditional-age and nontraditional-age college students. Adult Education Quarterly, 51(3), 236-249.

Keeley, J., Smith, D., \& Buskist, W. (2006). The teacher behaviors checklist: Factor analysis of its utility for evaluating teaching. Teaching of Psychology, 33(2), 84-91.

Lammers, W. J., \& Murphy, J. J. (2002). A profile of teaching techniques used in the university classroom a descriptive profile of a US public university. Active learning in higher education, $3(1), 54-67$.

Legon, R., \& Adair, D. (2013). Introduction to the Quality Matters program Retrieved on February 10, 2015 from:

https://www.qualitymatters.org/sites/default/files/Introduction\%20to\%20the\%20Quality\%20Mat ters\%20Program\%20HyperlinkedFinal2014.pdf.

Lehmann, I. J. (1963). Changes in critical thinking, attitudes, and values from freshman to senior years. Journal of Educational Psychology, 54(6), 305-315.

Major, C., \& Palmer, B. (2002). Faculty knowledge of influences on student learning. Peabody Journal of Education, 77(3), 138-162.

Minor, L. C., Onwuegbuzie, A. J., Witcher, A. E., \& James, T. L. (2002). Preservice teachers' educational beliefs and their perceptions of characteristics of effective teachers. Journal of Educational Research, 96, 116-127.

Mupinga, D. M., Nora, R. T., \& Yaw, D. C. (2006). The learning styles, expectations, and needs of online students. College Teaching, 54(1), 185-189.

Pascarella, E. T. (1980). Student-faculty informal contact and college outcomes. Review of educational research, 50(4), 545-595. 
Pascarella, E., \& Terenzini, P. (2005). How college affects students (Vol. 2): A third decade of research. San Francisco: Jossey Bass.

Pepe, J. W., \& Wang, M. C. (2012). What instructor qualities do students reward? College Student Journal, 46(3), 603-614.

Pozo-Munoz, C., Rebolloso-Pacheco, E., \& Fernandez-Ramirez, B. (2000). The'Ideal Teacher'. Implications for student evaluation of teacher effectiveness. Assessment \& Evaluation in Higher Education, 25(3), 253-263.

Redish, E. F., Saul, J. M., \& Steinberg, R. N. (1998). Student expectations in introductory physics. American Journal of Physics, 66(3), 212-224.

Reneau, F. (2011). Junior faculty perceptions of their doctoral level teaching preparation: A cross disciplinary examination. University of New Orleans Theses and Dissertations, Paper 1411.

Sander, P., Stevenson, K., King, M., \& Coates, D. (2000). University students' expectations of teaching. Studies in Higher Education, 25(3), 309-323.

Senko, C., Belmonte, K., \& Yakhkind, A. (2012). How students' achievement goals shape their beliefs about effective teaching: A 'build-a-professors' study. British Journal of Educational Psychology, 82(3), 420-435.

Shea, P. J., Pickett, A. M., \& Pelz, W. E. (2003). A follow-up investigation of "teaching presence" in the SUNY Learning Network. Journal of Asynchronous Learning Networks, 7(2), 61-80.

Shulman, L. (1987). Knowledge and teaching: Foundations of the new reform. Harvard Educational Review, 57, 1-22.

Sheridan, K., \& Kelly, M. A. (2010). The indicators of instructor presence that are important to students in online courses. MERLOT Journal of Online Learning and Teaching, 6(4), 767- 779.

Sikorski, J. F., Rich, K. B., Saville, B. K., Buskist, W., Drogan, O., \& Davis, S. F. (2001). Student use of introductory texts. Paper presented at the Teaching of Psychology Conference, Kennesaw, GA.

Silverman, S. (2003). The role of teaching in the preparation of future faculty. Quest, 55, 72-81. Smith, G. G., Ferguson, D., \& Caris, M. (2001). Online vs face-to-face. THE Journal (Technological Horizons in Education), 28(9), 18-26.

Song, L., Singleton, E. S., Hill, J. R., \& Koh, M. H. (2004). Improving online learning: Student perceptions of useful and challenging characteristics. The internet and higher education, 7(1), 59-70.

Soria, K. M., \& Stebleton, M. J. (2012). First-generation students' academic engagement and Journal of the Scholarship of Teaching and Learning, Vol. 16, No. 1, February 2016. 
retention. Teaching in Higher Education, 17(6), 673-685.

Swanson, S., Frankel, R. and Sagan, M. (2005). Exploring the impact of cultural differences, Marketing Education Review, 15(3), 37-48.

Tinto, V., Goodsell-Love, A. \&Russo. P. (1993). Building community among new college students. Liberal Education, 79, 16-21.

Toohey, S. (1999). Designing courses for higher education. Open University Press, 325 Chestnut Street, Philadelphia, PA.

Utecht, R. L., \& Tullous, R. (2009). Are we preparing doctoral students in the art of teaching? Research in Higher Education Journal, 4, 1-12.

Voss, R., Gruber, T., \& Szmigin, I. (2007). Service quality in higher education: The role of student expectations. Journal of Business Research, 60(9), 949-959.

Warburton, E. C., Bugarin, R., \& Nunez, A. M. (2001). Bridging the gap: Academic preparation and postsecondary success of first-generation students. Statistical analysis report. Postsecondary Education Descriptive Analysis Reports. Retrieved from: http://files.eric.ed.gov/fulltext/ED456168.pdf on March 25, 2015.

Webster, H., Freedman, M. B., \& Heist, P. (1962). Personality changes in college students. In Webster, H. Freedman, M., Heist, P. Sanford, Nevitt (Eds.), (1962). The American college: A psychological and social interpretation of the higher learning, (pp. 811-846). Hoboken, NJ, US: John Wiley \& Sons Inc. 